\title{
Treatment of early diabetic retinopathy with cyclandelate
}

\author{
J. G. CUNHA-VAZ, J. REIS FONSECA, AND J. R. B. HAGENOUW \\ From the Department of Ophthalmology, University of Coimbra, Coimbra, Portugal, and the \\ Department of Medical Affairs, Gist-Brocades NV, Delft, Holland
}

SUMMARY In order to assess the effect of cyclandelate on the abnormal permeability of the bloodretinal barrier which occurs in diabetic patients before any other lesions are apparent in the retina a well-controlled, double blind, and paired trial was carried out in 22 patients. The treatments were randomised. The permeability of the blood-retinal barrier was assessed by vitreous fluorophotometry. Each patient was examined before being involved in the trial and then another 3 times with 1 month's interval. The total duration of treatment was 3 months.

The results showed that the breakdown of the blood-retinal barrier as evidenced by the degree of abnormal fluorescein penetration into the vitreous suffered a significant decrease in the diabetic patients treated with cyclandelate when compared to the patients submitted to placebo administration, and this effect is particularly apparent in the third month of treatment.

It is now widely recognised that the major problem in diabetes mellitus does not arise acutely from lack of control of the carbohydrate metabolism, but from the insidiously developing vascular complications (Ditzel and Standl, 1975). The morbidity and incapacity associated with these complications are staggering, this being particularly true with diabetic retinopathy, which is nowadays one of the major causes of blindness.

In order to prevent this dramatic outcome it is necessary to detect the disease at a very early stage and to develop means of stopping its further progress. Its detection at a reversible stage and its immediate and effective treatment would be ideal.

It has recently been shown by our group that a significant disturbance of the blood-retinal barrier is present in diabetic patients with apparently normal fundi, this disturbance being apparently reversible (Cunha-Vaz et al., 1975). This was made possible by the introduction of vitreous fluorophotometry, a new clinical quantitative method for the study of the blood-retinal barrier.

There is also some evidence that from the early onset of the disease diabetics may suffer from inumerable cellular hypoxic injuries, caused by

This study was supported by research grant CMC 8 from the Instituto de Alta Cultura, Portugal.

Address for reprints: Professor José Cunha-Vaz, Clínica Oftalmológica, Hospitais da Universidade de Coimbra, Celas, Coimbra, Portugal. the association of an increase in oxygen demand (Joslin, 1923; White, 1939) and a disordered oxygen delivery (Ditzel and Rooth, 1955; Ditzel and Standl, 1975b).

It is therefore reasonable to consider the possibility that the oxygen-dependent active transport mechanisms of the blood-retinal barrier are altered by these fluctuations in tissue oxygen tension and that any drug which has a protective action against hypoxia may influence favourably the course of the disease.

Cyclandelate was the drug chosen for this trial because it has been shown to have a protective action against brain hypoxia (Funcke et al., 1974). In the past 10 years a number of papers have been published in which it was shown that cyclandelate treatment was followed by dilatation of cerebral vessels (Kuhn, 1966) and increased cerebral circulation (O'Brien and Veall, 1966). Improvement of mental functions in geriatric patients treated with the drug has been noted by Drift (1961), Ball and Taylor (1967), and others. These studies pointed, however, to an effect or effects of the drug on cerebral metabolism other than those indicated by a direct action on the tone of cerebral blood vessels. It has, indeed, been shown recently that cyclandelate enhances the resistance of rats and mice to hypoxia and attenuates or prevents the disturbances in the EEG of rats due to lack of oxygen (Funcke et al., 1974). Cyclandelate has also been shown to increase the penetration of glucose 
into rat brain, and it is now accepted that the therapeutic efficacy of cyclandelate in cerebrovascular insufficiency may be based not merely on improved blood flow but also on stimulation of active glucose uptake by the brain.

The aim of this study is therefore to assess the effect of cyclandelate on the permeability of the blood-retinal barrier in diabetic patients, before there are any apparent retinal lesions, and when a complete recovery may be expected.

\section{Method and evaluation}

The trial was started as well-controlled, double blind, and paired and completed as such. The treatments were randomised. The parameter measured was the permeability of the blood-retinal barrier as evidenced by the penetration of fluorescein after intravenous injection.

The trial was carried out with adult diabetic patients which were being followed up as outpatients in the Diabetes Clinic of Coimbra University Hospital. There were 6 men and 16 women, ranging from 26 to 80 years of age, and averaging 52.4 years. Patients having a history of eye disease or showing any retinal lesions were excluded from this trial. Only patients with maximal visual acuity, normal ophthalmoscopic and slit-lamp pictures, and normal retinal fluorescein angiography were admitted to the population.

Patients were admitted to the trial in 12 pairs. One member of each pair was treated with cyclandelate and the other with placebo. A patient who dropped out during the course of the trial was replaced, as well as the other from that pair. One of these pairs dropped out, however, only in the last month of the trial and could not be replaced. By the end of the trial there were, therefore, 11 pairs.

The details of the trial were explained to each patient and consent was obtained. Each individual was assigned to either cyclandelate or placebo, as determined by a table of random numbers.

The doses of cyclandelate were standardised at $400 \mathrm{mg} /$ capsule, 4 times daily. The total treatment duration was 3 months. The capsules of cyclandelate and placebo were provided by MycopharmaBrocades. The key to the randomisation codes was kept by the local pharmacist and was unknown to the examiners until the trial was completed. No other preparation with vascular effects was used by the patients during the course of the trial.

\section{Assessment of the permeability of the blood-retinal barrier}

The permeability of the blood-retinal barrier was assessed by vitreous fluorophotometry (Cunha-Vaz et al., 1975). The apparatus consisted essentially in a model 360 Haag-Streit slit-lamp which was modified by adapting a new source of illumination, appropriate filters, a photometric detection system, and a device for electrical registration of the movement of the instrument. Each patient was assessed 4 times, the first, before being involved in the trial, the second, at the end of the first month, the third at the end of the second month, and the fourth after the 3-month treatment. For these examinations a $10 \mathrm{ml}$ intravenous injection of $10 \%$ sodium fluorescein was immediately followed by fluorescence angiography, performed with the Topcon TRC-F3 and by vitreous fluorophotometry 1 hour later. The fluorophotometric curves were recorded by a Polaroid camera. Because the values in the anterior vitreous, near the lens, are variable and influenced by fluorescein penetration through anterior routes, only the posterior half of the curve was analysed. The lower area A as indicated in Fig. 1 was roughly integrated, this value representing a true value of the concentration of fluorescein in the posterior vitreous.

The values obtained for these areas in each patient are presented in Table 1 . These areas were named $A_{0}, A_{1}, A_{2}$, and $A_{3}$, according to the occasion of their recording, before the trial, after the first month, after the second month, or at the end of the third month, respectively.

The mean values of areas $0,1,2$, and 3 in each group of patients were first compared in order to detect any general difference in behaviour between the 2 groups.

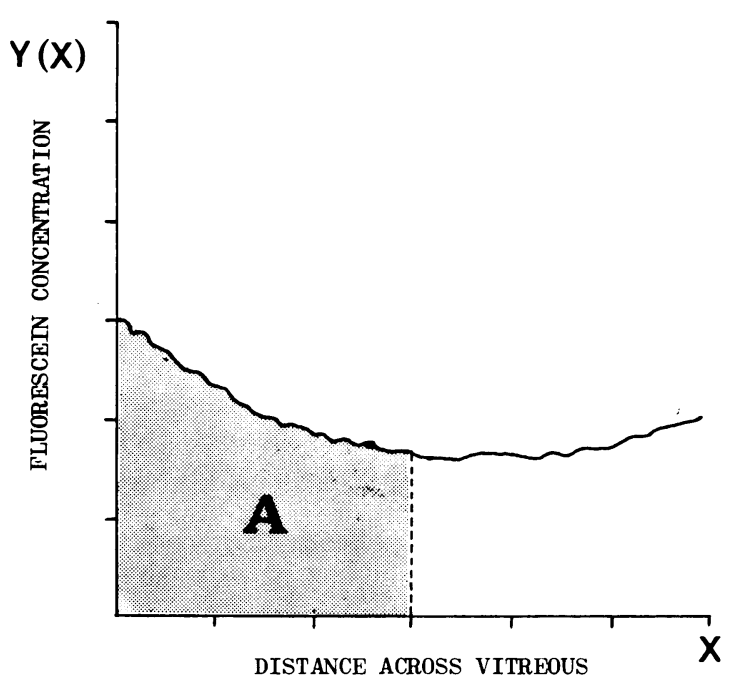

Fig. 1 Typical fluorophotometric curve. The lower area, A under the curve represents a true value of the concentration of fluorescein in the posterior vitreous 
Table 1 Values of fluorescein penetration into the posterior vitreous in the 4 examinations during the 3-month trial

\begin{tabular}{|c|c|c|c|c|c|c|c|c|c|c|c|c|c|}
\hline \multicolumn{7}{|l|}{ Placebo } & \multicolumn{7}{|c|}{ Cyclandelate } \\
\hline \multirow{2}{*}{ S. No. } & \multirow{2}{*}{ Age/Sex } & \multicolumn{4}{|c|}{ Fluorescein penetration } & \multirow{2}{*}{$\begin{array}{l}\text { Clinical } \\
\text { information }\end{array}$} & \multirow{2}{*}{ S. No. } & \multirow{2}{*}{ Age/Sex } & \multicolumn{4}{|c|}{ Fluorescein penetration } & \multirow{2}{*}{$\begin{array}{l}\text { Clinical } \\
\text { information }\end{array}$} \\
\hline & & $A_{0}$ & $A_{1}$ & $A_{2}$ & $A_{3}$ & & & & $A_{0}$ & $A_{1}$ & $A_{2}$ & $A_{3}$ & \\
\hline 1 & $60 / F$ & $6 \cdot 1$ & $7 \cdot 3$ & $9 \cdot 2$ & $9 \cdot 2$ & & 2 & $59 / \mathrm{F}$ & $3 \cdot 7$ & $6 \cdot 7$ & $8 \cdot 3$ & $7 \cdot 5$ & \\
\hline 4 & $50 / \mathrm{F}$ & $5 \cdot 4$ & $4 \cdot 1$ & 6.9 & $7 \cdot 0$ & & 3 & $80 / F$ & $9 \cdot 3$ & $9 \cdot 4$ & $11 \cdot 9$ & $10 \cdot 2$ & \\
\hline 6 & $47 / \mathrm{M}$ & $4 \cdot 4$ & $4 \cdot 0$ & 6.6 & $5 \cdot 9$ & & 5 & $51 / F$ & $4 \cdot 8$ & $5 \cdot 9$ & $9 \cdot 4$ & $9 \cdot 7$ & \\
\hline 8 & $42 / F$ & $3 \cdot 3$ & $6 \cdot 7$ & $5 \cdot 7$ & $8 \cdot 4$ & & 7 & $55 / \mathrm{M}$ & $4 \cdot 6$ & $6 \cdot 3$ & $9 \cdot 1$ & $9 \cdot 1$ & $\begin{array}{l}\text { Minimal hard } \\
\text { exudates }\end{array}$ \\
\hline 9 & $33 / F$ & $6 \cdot 7$ & $6 \cdot 5$ & 6.6 & 6.9 & & 10 & $26 / F$ & $5 \cdot 4$ & $7 \cdot 9$ & $4 \cdot 7$ & $4 \cdot 8$ & \\
\hline 12 & $68 / M$ & $7 \cdot 5$ & $7 \cdot 6$ & $8 \cdot 4$ & $9 \cdot 6$ & & 11 & $57 / \mathrm{M}$ & $6 \cdot 2$ & 6.0 & $7 \cdot 1$ & $4 \cdot 9$ & \\
\hline 15 & $64 / F$ & $5 \cdot 9$ & $5 \cdot 9$ & $9 \cdot 2$ & $10 \cdot 3$ & Minimal hard exudates & 16 & $42 / F$ & $7 \cdot 8$ & $6 \cdot 0$ & $7 \cdot 0$ & $5 \cdot 4$ & \\
\hline 18 & $44 / M$ & $4 \cdot 4$ & $4 \cdot 0$ & $5 \cdot \overline{5}$ & $5 \cdot 5$ & & 17 & $66 / F$ & $4 \cdot 7$ & $7 \cdot 0$ & $8 \cdot 2$ & $8 \cdot 2$ & \\
\hline 20 & $46 / F$ & $3 \cdot 6$ & $6 \cdot 8$ & $10 \cdot 2$ & $9 \cdot 1$ & & 19 & $60 / F$ & $4 \cdot 6$ & $6 \cdot 1$ & $7 \cdot 6$ & $6 \cdot 5$ & \\
\hline 21 & $49 / \mathrm{M}$ & $1 \cdot 7$ & $3 \cdot 7$ & $5 \cdot 3$ & $7 \cdot 6$ & $\begin{array}{l}\text { Hard exudates; signs of } \\
\text { leakage on angiography }\end{array}$ & 22 & $50 / F$ & $2 \cdot 2$ & $3 \cdot 6$ & $7 \cdot 5$ & 4.9 & \\
\hline 26 & $42 / F$ & $4 \cdot 8$ & $4 \cdot 0$ & $8 \cdot 7$ & $10 \cdot 0$ & $\begin{array}{l}\text { Signs of leakage on } \\
\text { angiography }\end{array}$ & 25 & $61 / F$ & $6 \cdot 0$ & $6 \cdot 4$ & $7 \cdot 7$ & $6 \cdot 7$ & \\
\hline Mean & & $4 \cdot 89$ & $5 \cdot 51$ & $7 \cdot 48$ & $8 \cdot 14$ & & & & $5 \cdot 39$ & $6 \cdot 48$ & $8 \cdot 05$ & $7 \cdot 08$ & \\
\hline
\end{tabular}

The parameter that was used to test efficacy of the drug $v$. the placebo was the difference between the fluorescein concentrations in the posterior vitreous at the final examination, represented by $A_{3}$, and the fluorescein concentrations at the previous visits $\left(A_{2}, A_{1}\right.$, and $\left.A_{0}\right)$.

For each patient (11 drug, 11 placebo) these differences $\left(A_{3}-A_{0}, A_{3}-A_{1}\right.$, and $\left.A_{3}-A_{2}\right)$ were subjected to statistical analysis. A final complementary analysis was made taking into account simultaneously for each patient, the differences $A_{1}-A_{0}$ and $A_{3}-A_{2}$, in order to highlight the corrective action of the drug on the abnormal permeability of the blood-retinal barrier. $A_{1}-A_{0}$ represents the natural evolution of the disease, the effect of treatment being then minimal; $A_{3}-A_{2}$ represents best the effect of treatment.

The following standard statistical methods were used: Student's $t$ test and standard deviation.

\section{CLINICAL ASSESSMENT}

The visual acuity was tested for each patient and he was examined 4 times by ophthalmoscopy, during the course of the trial, at the beginning and at the end of each month.

\section{Results}

Assessment of the permeability of the blood-retinal barrier by vitreous fluorophotometry

The mean values of the areas under the fluorophotometric curves, representing the fluorescein penetration into the posterior half of the vitreous, obtained from each patient (11 placebo, 11 cyclandelate) and from the 4 examinations were graphically plotted (Fig. 2). The figure shows a well-defined pattern of progressive increase in the permeability
Fig. 2 Patterns of fluorescein penetration into the posterior vitreous, in placebo and cyclandelate treated patients, during the 3-month trial

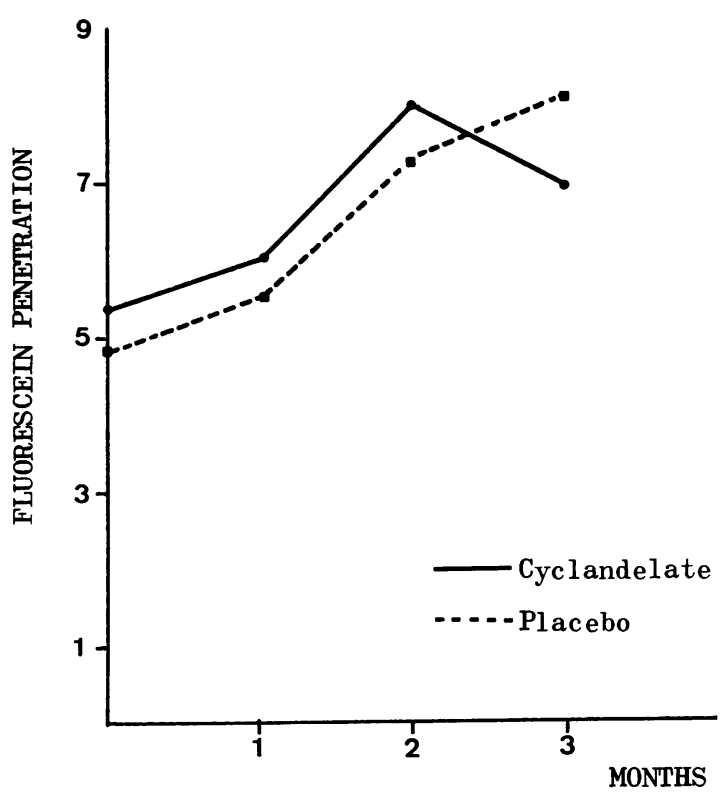

of the blood-retinal barrier, well evidenced by the increased fluorescein penetration into the vitreous, in the placebo-treated patients, during the 3-month period of the trial. This pattern appeared, however, to be completely inverted during the third month of treatment in the patients receiving cyclandelate, suggesting a definite improvement in the conditions of abnormal permeability of the blood-retinal barrier which characterises the early stages of retinal involvement in diabetes. 
Table 2 Differences in fluorescein penetration into the posterior vitreous between the last $\left(A_{3}\right)$ and the initial examination $\left(A_{0}\right)$

\begin{tabular}{|c|c|c|c|}
\hline \multicolumn{2}{|l|}{ Placebo } & \multicolumn{2}{|c|}{ Cyclandelate } \\
\hline Series No. & $A_{3}-A_{0}$ & Series No. & $A_{3}-A_{0}$ \\
\hline $\begin{array}{l}1 \\
4 \\
6 \\
8 \\
9 \\
12 \\
15 \\
18 \\
20 \\
21 \\
26 \\
\text { Mean } \\
\pm \text { SD }\end{array}$ & $\begin{array}{l}+3.1 \\
+1.6 \\
+1.5 \\
+5.1 \\
+0.2 \\
+2.1 \\
+4.4 \\
+1.1 \\
+5.5 \\
+5.9 \\
+5.2 \\
+3.2 \\
\pm 0.616\end{array}$ & $\begin{array}{r}2 \\
3 \\
5 \\
7 \\
10 \\
11 \\
16 \\
17 \\
19 \\
22 \\
25\end{array}$ & $\begin{array}{l}+3.8 \\
+0.9 \\
+4.9 \\
+4.5 \\
-0.6 \\
-1.3 \\
-2.4 \\
+3.5 \\
+1.9 \\
+2.7 \\
+0.7 \\
+1.6 \\
\pm 0.736\end{array}$ \\
\hline
\end{tabular}

$t=1 \cdot 74 ; \mathrm{DF}=20 ; 0.1<\mathrm{P}>0.05$.

This finding is substantiated when the differences in fluorescein concentration in the posterior vitreous between the last and the previous visits were analysed and the values obtained from patients given placebo capsules compared with the values obtained from cyclandelate-treated patients. The differences in fluorescein penetration, i.e., breakdown of the bloodretinal barrier, between the last visit $\left(A_{3}\right)$ and the initial examination $\left(\mathbf{A}_{0}\right)$ are significantly different at the $10 \%$ level between the 2 groups of patients, placebo and cyclandelate $(t=1 \cdot 74 ; \mathrm{DF}=20 ; 0 \cdot 1$ $<\mathbf{P}>0.05$; Table 2).

This level of significance increases, however, when the differences in fluorescein penetration are taken between the last visit and the second and third examinations, after 1 and 2 months of treatment, respectively. The differences between the last visit and the second examination $\left(\mathbf{A}_{3}-\mathbf{A}_{1}\right)$, between the 2 groups of patients, are significant at the $2 \%$ level $(t=2.7 ; \mathrm{DF}=20 ; 0.02<\mathrm{P}>0.01$; Table 3$)$. Finally,

Table 3 Differences in fluorescein penetration into the posterior vitreous between the end of the trial $\left(A_{3}\right)$ and the end of the first month $\left(A_{1}\right)$

\begin{tabular}{|c|c|c|c|}
\hline \multicolumn{2}{|l|}{ Placebo } & \multicolumn{2}{|c|}{ Cyclandelate } \\
\hline Series No. & $A_{3}-A_{1}$ & Series No. & $A_{3}-A_{1}$ \\
\hline $\begin{array}{l}1 \\
4 \\
6 \\
8 \\
9 \\
12 \\
15 \\
18 \\
20 \\
21 \\
26 \\
\text { Mean } \\
\pm \text { SD }\end{array}$ & $\begin{array}{l}+1.9 \\
+2.9 \\
+1.9 \\
+1.7 \\
+0.4 \\
+2.0 \\
+4.4 \\
+1.5 \\
+2.3 \\
+3.9 \\
+6.0 \\
+2.6 \\
\pm 0.475\end{array}$ & $\begin{array}{r}2 \\
3 \\
5 \\
7 \\
10 \\
11 \\
16 \\
17 \\
19 \\
22 \\
25\end{array}$ & $\begin{array}{l}+0.8 \\
+0.8 \\
+3.8 \\
+2.8 \\
-3.1 \\
-1.1 \\
-0.6 \\
+1.2 \\
+0.4 \\
+1.3 \\
+0.3 \\
+0.6 \\
\pm 0.534\end{array}$ \\
\hline
\end{tabular}

Table 4 Differences in fluorescein penetration into the posterior vitreous between the end of the trial $\left(A_{3}\right)$ and the end of the second month $\left(A_{2}\right)$

\begin{tabular}{lcccc}
\hline \multicolumn{3}{l}{ Placebo } & \multicolumn{3}{c}{ Cyclandelate } \\
\cline { 2 - 3 } Series No. & $A_{3}-A_{2}$ & & Series No. & $A_{3}-A_{2}$ \\
\hline 1 & 0 & 2 & -0.8 \\
4 & +0.1 & 3 & -1.7 \\
6 & -0.7 & 5 & +0.3 \\
8 & +2.7 & 7 & 0 \\
9 & +0.3 & 10 & 0.1 \\
12 & +1.2 & 11 & -2.2 \\
15 & +1.1 & 16 & -1.6 \\
18 & 0 & 17 & 0 \\
20 & -1.1 & 19 & -1.1 \\
21 & +2.3 & 22 & -2.6 \\
26 & +1.3 & 25 & -1.0 \\
Mean & +0.65 & & -0.96 \\
\pm SD & \pm 0.357 & & \pm 0.298 \\
\hline
\end{tabular}

$t=3.6 ; \mathrm{DF}=20 ; 0.005<\mathrm{P}>0.001$.

the differences between the final observation and the third examination $\left(A_{3}-A_{2}\right)$ show a highly significant difference between the 2 groups of patients $(t=3.6 ; \mathrm{DF}=20 ; 0.005<\mathrm{P}>0.001$; Table 4). These results show clearly that cyclandelate has a beneficial effect upon the breakdown of the bloodretinal barrier which is present in the early stages of diabetic retinopathy, preventing its progressive increase, well evidenced in patients receiving placebo capsules. The results indicate also that this beneficial effect is particularly marked after a period of treatment of 2 months. The fact that the full effect of cyclandelate is especially well evidenced in the third month of treatment, in contrast to the first month when its activity appears to be minimal, prompted us to compare the differences between the third month of treatment $\left(A_{3}-A_{2}\right)$ and the first month $\left(A_{1}-A_{0}\right)$, i.e. $\left(A_{3}-A_{2}\right)-\left(A_{1}-A_{0}\right)$ between the 2 groups. The statistical analysis of these differences shows a highly significant difference between the 2 groups $(t=4.4 ; \mathrm{DF}=20 ; \mathrm{P}<0.001$; Table 5).

These results indicate clearly that the breakdown of the blood-retinal barrier as evidenced by the degree of abnormal fluorescein penetration into the vitreous suffered a significant decrease in the diabetic patients treated with cyclandelate when compared to the patients submitted to placebo administration, and that this effect is particularly apparent after 2 months of treatment.

\section{CLINICAL ASSESSMENT}

The other examinations performed agree, although in a less clear manner, with the fluorophotometric results. As regards the clinical picture, the cases under study are of such nature that only signs of worsening can be accepted as true changes. The visual acuity remained maximal in every patient 
Table 5 Differences in fluorescein penetration between the third month of the trial $\left(A_{3}-A_{2}\right)$ and the first month $\left(A_{1}-A_{0}\right)$

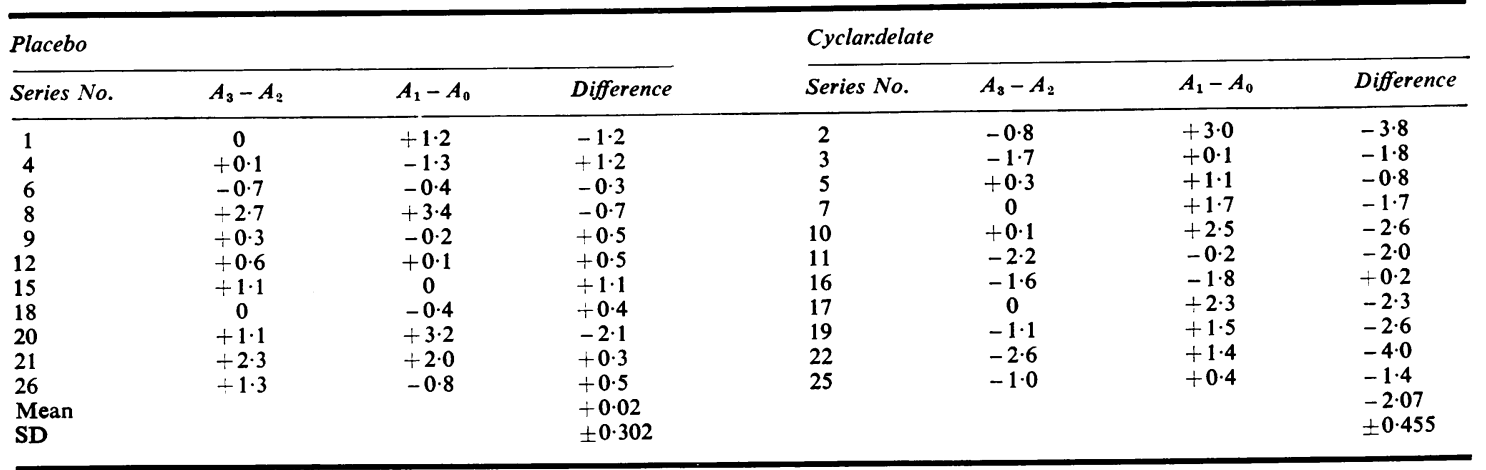

$t=4.4 ; \mathrm{DF}=20 ; \mathrm{P}<0.001$.

during the entire trial. Ophthalmoscopically and angiographically, however, slight changes developed in the fundi of 3 patients receiving placebo and in 1 patient receiving cyclandelate (Table 1). These included the development of minimal hard exudates or some angiographical evidence of fluorescein leakage. The angiographical changes were observed in 2 placebo patients at the last examination, whereas the hard exudates were seen with the ophthalmoscope in 3 placebo-treated patients and in only 1 receiving cyclandelate. An overall clinical impression was, therefore, obtained of more marked progression of the retinal involvement in the diabetics not receiving cyclandelate.

\section{SIDE-EFFECTS}

Two patients complained of nausea. This was sufficient to provoke in 1 patient discontinuation of treatment and the consequent dropping out of the respective pair and its substitution with a new pair. It is interesting, however, to note that the second patient who complained of nausea was receiving the placebo capsules.

\section{Discussion}

The present trial has shown that cyclandelate in doses of $400 \mathrm{mg} /$ capsule, 4 times daily, given for a period of 3 months, has significant beneficial effect upon the breakdown of the blood-retinal barrier which is present in the early stages of retinal involvement in diabetes. The use of vitreous fluorophotometry, a clinical quantitative method of evaluation of the permeability of the blood-retinal barrier, allowed the results to be subjected to statistical analysis. This showed that the progressive deterioration of the blood-retinal barrier observed in the diabetic patients receiving placebo capsules during the 3-month trial was arrested in the patients receiving cyclandelate. This beneficial effect of cyclandelate was particularly marked in the third month of treatment, when the levels of breakdown of the blood-retinal barrier decreased significantly, pointing to some recovery of the disease process, and suggesting even better results from prolonged periods of treatment. In a less clear manner the clinical impression obtained from ophthalmoscopy and fluorescence angiography agreed with the results obtained, showing an apparently more rapid progression of the disease in the placebo-treated diabetics. It remains now to be seen if these results can be confirmed by long-term studies and if the progression and development of the full picture of diabetic retinopathy and final loss of vision can be prevented by prolonged treatment with cyclandelate.

The results here reported showing a favourable effect of cyclandelate on the abnormal permeability of the blood-retinal barrier in the earlier stages of diabetic retinopathy are probably due to the protective action of the drug against hypoxia (Funcke et al., 1974). It is to be recalled that an increase in retinal blood flow by direct action on the tone of the retinal vessels would not appear to have any beneficial effect, according to recent personal observations (Cunha-Vaz et al., 1977), which showed an apparent direct correlation between increase in retinal blood flow and progression of diabetic retinopathy.

The demonstration of a beneficial effect of cyclandelate in early diabetic retinal involvement supports the work of Ditzel and Standl (1975a, b) and substantiates the hypothesis that fluctuations in tissue oxygen tension may be responsible for the retinal vascular complications in diabetes. Examination of the effect of this drug upon other vascular complications of diabetes may help to indicate if 
these variations in tissue oxygen tension are a general phenomenon of paramount importance in every vascular complication of diabetes or if they assume a particular significance in the retina, a tissue well known for its high metabolic needs.

Our thanks are due to Professor J. P. Lima, from the Physics Department of the University of Coimbra, for reviewing the statistical evaluations and to Miss M. João Coelho for secretarial help.

\section{References}

Ball, J. A. C., and Taylor, E. R. (1967). British Medical Journal, 3, 525.

Cunha-Vaz, J. G., Faria de Abreu, J. R., Campos, A. J., and Figo, G. M. (1975). British Journal of Ophthalmology, 59, 649 .

Cunha-Vaz, J. G., Fonseca, J. R., Faria de Abreu, J. R., and Lima, J. J. P. (1977). Investigative Ophthalmology (submitted for publication).

Ditzel, J., and Rooth, G. (1955). Diabetes, 4, 474.

Ditzel, J., and Standl, E. (1975a). Acta Medica Scandinavica, Supplement, 578, 49.

Ditzel, J., and Standl, E. (1975b). Acta Medica Scandinavica, Supplement, 578, 59 .

Drift, J. H. A. van der (1961). Angiology, 12, 401.

Funcke, A. B. H., van Beek, M. C., and Nijland, K. (1974). Current Medical Research, 2, 37.

Joslin, E. P. (1923). Diabetic Metabolism with High and Low Diets. Publication No. 323. Carnegie Institute of Washington.

Kuhn, L. A. (1966). Angiology, 17, 422.

O'Brien, M. D., and Veall, M. (1966). Lancet, 2, 729.

White, P. (1939). Archives of Internal Medicine, 63, 39. 